\title{
Improvement of Rail-sea Multimodal Transport with Dry Port Construction: Case Study of Ningbo-Zhoushan Port
}

\author{
Feng Sun ${ }^{1}$, Xuefeng Wang ${ }^{2}$, , Lin Jin ${ }^{1}$, Yeru Shi ${ }^{2}$ \\ ${ }^{1}$ Institute of Logistics Science \& Engineering, Shanghai Maritime University, Shanghai, China \\ ${ }^{2}$ College of Transport \& Communications, Shanghai Maritime University, Shanghai, China \\ Email address: \\ Felix_sf1602@hotmail.com (Feng Sun),wangxf@shmtu.edu.cn (Xuefeng Wang) \\ *Corresponding author
}

\section{To cite this article:}

Feng Sun, Xuefeng Wang, Lin Jin, Yeru Shi. Improvement of Rail-sea Multimodal Transport with Dry Port Construction: Case Study of Ningbo-Zhoushan Port. Science Journal of Business and Management. Vol. 5, No. 2, 2017, pp. 78-87. doi: 10.11648/j.sjbm.20170502.16

Received: February 28, 2017; Accepted: March 27, 2017; Published: April 6, 2017

\begin{abstract}
For interaction between dry port and sea port, rail-sea multimodal transport is the main transportation and organization mode. The extended construction of corridors of rail-sea multimodal transport needed to be studied further. It will help to establish unified mechanism of transportation coordination, realize compatible standard transport rules, and promote the development of enterprises of sea and dry ports. Take Ningbo-Zhoushan sea port as an example, the options of multimodal transport corridors from Ningbo-Zhoushan to southwest areas are analyzed and optimized. In this paper, a TOPSIS decision model based on entropy weight is proposed, helping to effectively select the optimal multimodal transport plan. It is concluded that the best transport plan of 20 feet container from Ningbo-Zhoushan to Chengdu and Guiyang is the direct railway transport. The best transport plan of 20 feet container from Ningbo-Zhoushan to Kunming is the goods transported by rail from Ningbo-Zhoushan to Chongqing and then road from Chongqing to Kunming. Finally, it is suggested that promote the extension and radiation of port function and invest in the construction and operation of dry port.
\end{abstract}

Keywords: Rail-sea Multimodal Transport, Dry Port, Sea Port, TOPSIS Decision Model, Optimization

\section{Introduction}

Rail-sea multimodal transport means cargo is transported by rail to the sea port for shipping or by ship to the sea port for railway transportation. The whole process of transportation requires one declaration, one inspection and one release.

The definition of dry port is on the basis of sea port. The dry port developed in inland area is hoping to expand inland cargo for sea port, attracting trade and extending business [1-2]. Rail-sea multimodal transport is the main transportation and organization mode for dry port interacting with sea port [3]. Some dry ports are also called international land ports, because of the differential function of importing and exporting cargo in inland area by rail and road [4].

Taken Ningbo-Zhoushan sea port as an example, the dry ports are positively established to open rail-sea multimodal transport corridor, bringing to increase of container. Ningbo-Zhoushan sea port already has twelve dry ports including three out of local province, which are Xiangyang, Shangrao and Yingtan. Dry ports of Ningbo-Zhoushan have functions of cargo organization, container provision and supervision, inland truck short barge and rail agency, which make great contribution for rail-sea intermodal container. Ningbo-Zhoushan port sets up a branch in Jiangxi and work office in Xinjiang. The service platform of rail-sea multimodal transport is built to coordinate the organization of railway transport and promote the development of multimodal transport of Ningbo-Zhoushan port [5]. Ningbo-Zhoushan port develops rail-sea multimodal transport with Chongqing and provinces of Zhejiang, Jiangxi, Anhui, Hubei, Sichuan, Xi'an and Xinjiang. Seven container trains of rail-sea multimodal transport have been launched, including Shaoxing, Yiwu, Jinhua, Lanxi, Taizhou, Hefei, Yintan-Shangrao ones. The Chengdu-Chongqing container train will also be set up in the future [6]. In 2015, the container volume of rail-sea multimodal transport of Ningbo-Zhoushan port is 170,500 TEU, with an increase of $26.2 \%$. The growth rate continues to rank in advance of 
Chinese coastal ports.

For further development of Ningbo-Zhoushan port, the extended construction of rail-sea multimodal transport needed to be studied, especially in Chinese western areas.

\section{Related Works}

Nowadays the concept of dry port is defined clearly and its development is national wide cover. In general, there is a distinct gradual stage and characteristic of dry port's development [7]. However, there is still a strong internal and consist logic during the whole period. The main goal is enhancing the level of logistics services and serving the regional economic development [8].

The development of Chinese dry port has gone through three stages. The primary stage of its theory and practice is from 2000 to 2006. China entered into the World Trade Organization in December 11, 2001. It directly promoted the development of Chinese dry port. The key point of dry port development is the convenience of customs clearance. Many inland cities and coastal ports are not in the same customs territory. Inland cargo needs to be transited across different customs. This leads to low clearance efficiency and long clearance time. This does no help to shorten the time of settlement and tax rebate and circulate enterprise fund [9]. Therefore, the accession to the WTO provides a good opportunity for the development of Chinese export-oriented economy, and puts forward new requirements for further improvement of port efficiency. Chinese first dry port project was set up in October 2002. The start of dry port marked with the cooperation between Tianjin port and Beijing's Chaoyang dry port. The further developed stage of theory and practice of dry port is from 2006 to 2012. The US subprime mortgage crisis in 2007 leaded to outbreak of the global financial crisis in 2008. It had negative impact on the development of Chinese dry port [10]. Therefore, a large number of international logistics ports were built to meet the needs of the development of international trade in national wide areas. It helped to strengthen the logistics infrastructure construction, accelerate the development of rail-sea multimodal transport and improve the capacity of international cargo transit [11]. It helped to speed up the development of international logistics to meet the needs of international transit, procurement, distribution and entrepot business [12]. The mature stage of theory and practice of dry port is from 2012 to 2016. President Xi Jinping made a major initiative of One Belt and One Road in 2013. It provided an excellent opportunity for development of Chinese dry port. The key point of transport development is the key corridors, nodes and projects of traffic infrastructure [13]. Besides this, the missing sections needs to be opened up in advance and the road bottlenecks needs to be smoothed [14]. The road safe and protected facilities and traffic management equipment are also improved to enhance the level of road convenience. The whole and unified mechanism of transportation coordination are established and promoted. It will help to connect the international customs, reload and multimodal transport. The compatible standard transport rules and international transport facilitation will be realized. Port infrastructure constructions are promoted. The corridor of multimodal transport is clear. The cooperation of port construction is promoted. The government plays a guiding role in the construction of dry port. The enterprises are the driving force for promoting the development of dry port [15].

The container hub port is centered in the rail-sea multimodal transport. It connects with river port, feeding port, feeder port and railway container handling station, helping to expand the main port's attraction of container cargo and extend to the inland hinterland center [16]. Every dry port's freight station will attract suitable container cargo to a certain extent. The container freight station and transportation route are formed with outward radiate economic zone like point-linear shape [17]. A complete industrial chain of container transport is formed for the development of gradient logistics corridor.

The meaning of corridor of container rail-sea multimodal transport should be analyzed from hardware and software composition. The hardware structure is the necessary foundation of container transportation [18]. It includes infrastructure equipment, railway network, harbor, corridor, wharf, yard, etc. The software structure is the guarantee of standardization, order and intelligence of container transportation. It includes the relevant policy guidance, information technology and platform, advanced management level, etc. Chinese government carried out six demonstrated project of container rail-sea multimodal transport since 2011, including areas of Dalian - northeast, Tianjin - north and northwest, Qingdao - Zhengzhou and Longhai nearby, Lianyungang - Alataw Pass nearby, Ningbo - east and Shenzhen - south and southwest. This project takes advantages of railway container transportation, including energy saving, environmental protection, large volume, less limited with weather conditions and wide range of distributed points [19]. The combination of rail and sea transport is powerfully to enhance the competitiveness of shipping enterprises, alleviate the transportation pressure of port city and improve the quality and level of port development.

\section{Research Methodology in Route Way Research}

\subsection{Mathematical Model}

The construction of container multimodal transport corridor is quite complicated. The research on the mode and route of transportation needs to be considered with external environmental factors. Personal factors will influence the accuracy of decision making. In order to minimize the impact of human factors, the target selection in different situations needs to be quantified to make the final choice. In this paper, a TOPSIS decision model based on entropy weight is proposed, which can effectively solve the problem of weight distribution and optimal transportation plan selection [20-23].

It is assumed that $x_{i j}$ representing the evaluation index (1 
$\leqslant \mathrm{j} \leqslant \mathrm{n})$ with several transportation plans $(1 \leqslant \mathrm{i} \leqslant \mathrm{m})$, establishing the initial matrix.

$$
\left(X_{i j}\right)_{m \times n}=\left(\begin{array}{cccc}
X_{11} & X_{21} & \ldots & X_{m 1} \\
X_{12} & X_{22} & \ldots & X_{m 2} \\
\ldots & \ldots & \ldots & \ldots \\
X_{1 n} & X_{2 n} & \ldots & X_{m n}
\end{array}\right)
$$

(1) The value of the initial matrix is normalized. The proportion $x_{i j}$ of index value $\mathrm{j}$ of transport scheme $\mathrm{i}$ is obtained by formula 2 .

$$
X_{i j}^{\prime}=X_{i j} / \sum_{i=1}^{m} X_{i j}
$$

The complete normalized matrix $\left(X_{i j}^{\prime}\right)_{m \times n}$ will be built.

$$
\left(X_{i j}^{\prime}\right)_{m \times n}=\left(\begin{array}{cccc}
X_{11}^{\prime} & X_{21}^{\prime} & \ldots & X_{m 1}^{\prime} \\
X_{12}^{\prime} & X_{22}^{\prime} & \ldots & X_{m 2}^{\prime} \\
\ldots & \ldots & \ldots & \ldots \\
X_{1 n}^{\prime} & X_{2 n}^{\prime} & \ldots & X_{m n}^{\prime}
\end{array}\right)
$$

(2) Each index entropy is calculated. Entropy is derived from the concept of engineering thermodynamics. It is an effective quantitative decision method, applied to the analysis of economic and social analysis. In the concept of information theory, information entropy is a uncertain value of the whole system in disorder. It is assumed that there are $\mathrm{n}$ kinds of different states in the system, and the probability value of each condition will be $P_{j}(X)(j=1,2, \cdots, n)$, then the relative entropy algorithm is calculated.

$$
E(X)=-\frac{1}{\ln n} \sum_{j=1}^{n} P_{j}(X) \ln P_{j}(X)
$$

The normalized matrix is substituted into formula 4 to obtain entropy value under the evaluation index $\mathrm{j}$ with transport scheme $\mathrm{m}$.

$$
E\left(X_{j}\right)=-\frac{1}{\ln m} \sum_{i=1}^{m} X_{i j}^{\prime} \ln X_{i j}^{\prime}
$$

(3) The coefficient $H_{j}$ of variation is calculated with formula 6 .

$$
H_{j}=1-E\left(X_{j}\right)
$$

$H_{j}$ represents the degree of differentiation of the index $\mathrm{j}$. The minor value of $H_{j}$ means less use and impact of the index j. On the contrary, the biggish value of $H_{j}$ means more use and impact of the index $\mathrm{j}$.

(4) The weight of entropy is calculated with formula 7.

$$
\theta_{j}=H_{j} / \sum_{j=1}^{n} H_{j}
$$

$\theta_{j}$ represents the entropy value of the index $\mathbf{j}$.

(5) The weighted and normalized matrix built. The weight value of entropy is calculated by the index of different schemes and formula 7 . The normalized matrix will be found.

$$
\left(V_{i j}\right)_{m \times n}=\left(\begin{array}{cccc}
\theta_{1} X_{11}^{\prime} & \theta_{1} X_{21}^{\prime} & \ldots & \theta_{1} X_{m 1}^{\prime} \\
\theta_{2} X_{12}^{\prime} & \theta_{2} X_{22}^{\prime} & \ldots & \theta_{2} X_{m 2}^{\prime} \\
\ldots & \ldots & \ldots & \ldots \\
\theta_{n} X_{1 n}^{\prime} & \theta_{n} X_{2 n}^{\prime} & \ldots & \theta_{n} X_{m n}^{\prime}
\end{array}\right)
$$

(6) Positive and negative ideal solutions are confirmed.

$$
\begin{aligned}
& V^{+}=\left\{\left(\max _{i} V_{i j} \mid j \in J_{1}\right),\left(\min _{i} V_{i j} \mid j \in J_{2}\right)\right\} \\
& V^{-}=\left\{\left(\min _{i} V_{i j} \mid j \in J_{1}\right),\left(\max _{i} V_{i j} \mid j \in J_{2}\right)\right\}
\end{aligned}
$$

$\mathrm{i}=1,2, \cdots, \mathrm{m}, J_{1}$ represents benefit index, $J_{2}$ represents cost index.

(7) The distances between each transport plan and $V^{+}, V^{-}$ are calculated.

$$
\begin{gathered}
d_{i}^{+}=\left[\sum_{j=1}^{n}\left(V_{i j}-V_{j}^{+}\right)^{2}\right] / 2 \\
d_{i}^{-}=\left[\sum_{j=1}^{n}\left(V_{i j}-V_{j}^{-}\right)^{2}\right] / 2 \\
\mathrm{i}=1,2, \ldots, \mathrm{m}
\end{gathered}
$$

(8) The degree of closeness of each transport plan with ideal solution are calculated.

$$
C_{i}=\frac{d_{i}^{-}}{d_{i}^{-}+d_{i}^{+}}(i=1,2, \cdots, m)
$$

The value of $C_{i}$ is greater, the transport plan is more ideal.

\subsection{Index System}

\subsubsection{Transportation Distance (D)}

The distance of transportation refers to the total distance of goods originated to the destination. In general, The railway and waterway are suitable for long distance transportation, while the highway is suitable for transportation of first mile, last mile and short distance.

\subsubsection{Transportation Cost (P)}

The transportation cost is spent to complete the transportation of goods from the departure to the destination. It is determined by the key factor in the multimodal transport options. It includes the cost spent in transport, transit, storage and other additional activities.

\section{A. Calculation of road freight fee}

The pricing principle is according to the price and value of road transport of container. In general, it is charged by different specifications of empty or heavy container. As known, the basic price of 20 feet standard and heavy container is $6 \mathrm{USD} / \mathrm{TEU} \mathrm{km}$, and the basic price of 40 feet standard and heavy container is 9 USD/TEU $\mathrm{km}$. The road 
freight fee $P_{k}$ is represented by formula 12 .

$$
P_{k}=a_{k} * L^{*} n+m_{k}^{*} n+r
$$

$a_{k}$ is the basic price of heavy (empty) container (RMB/TEU); $m_{k}$ is the basic price of each container once ( $\mathrm{RMB} / \mathrm{TEU}) ; \mathrm{L}$ is the transport distance (kilometer); $\mathrm{n}$ is the volume of container; $r$ is the additional cost (RMB).

$m_{k}$ needs to considered in the short distance transport. The case study is considered about the long distance transport, thus $m_{k}$ is ruled out.

B. Calculation of railway freight fee

The railway freight fee is generally calculated in accordance with the used container number and the container freight rate stipulated in the railway freight rate table. It mainly contains the following four categories.

a) Basic railway freight fee

It is necessary to maintain the normal operation of the railway transport. The railway freight fee $P_{i}$ is represented by formula 13 .

$$
P_{i}=\left(k_{j}+f_{j} * f_{1}\right) * n
$$

$P_{i}$ is the basic railway freight fee (RMB); $k_{j}$ is the basic price of each container from departure to destination $(\mathrm{RMB} / \mathrm{TEU}) ; f_{j}$ is the basic operational price (RMB/TEU per kilometer); $f_{1}$ is the transport distance (kilometer); $\mathrm{n}$ is the volume of container.

The basic price of $k_{j}$ and $f_{j}$ are represented in Table 1.

Table 1. The Basic Price of Standard Railway Container Transportation.

\begin{tabular}{llll}
\hline $\boldsymbol{k}_{\boldsymbol{j}}$ & & $\boldsymbol{f}_{\boldsymbol{j}}$ & \\
\hline Price & Unit & Price & Unit \\
215 & RMB/TEU & 0.9274 & RMB/TEU per kilometer \\
\hline
\end{tabular}

b) Railway construction fund

It is considered about the extra fee paid according with the proportion of the total freight fee. It is used to maintain the railway construction and preservation. As for 20 feet standard containers, the general charge is $0.528 \mathrm{RMB} / \mathrm{TEU} \mathrm{km}$.

c) Railway electrification cost

When the train travels to the electrified section, it is necessary to add cost to fill the electricity consumption of the electrified section. In this paper, there is little section of railway electrification from Ningbo to southwest, thus the electrification cost is negligible.

d) Additional fees

Additional fees contain shared fee of new railway, railway equipment usage fee, handling fee, auxiliary work and so on. These charges are used to meet the railway operating expenses and ensure the railway transport with certain profit.

\subsubsection{Transportation Time (T)}

The transportation time is the sum time consumed from departure to destination. In practice, it contains travel time of each section, cargo loading and unloading time in the transfer station and the storage time.

In general, the average speed of road transportation in China is $90 \mathrm{~km} / \mathrm{h}$. The average speed of railway transportation is $80 \mathrm{~km} / \mathrm{h}$. The average speed of waterway transport in Yangtze River is about $13 \mathrm{knots}(24 \mathrm{~km} / \mathrm{h})$. There is a direct relationship between the transit time and the transportation distance. Certain time is consumed in the transit or transshipment operation of container transport. The transport time is affected by the resistance factors in the transportation. Generally speaking, the key factor affecting the transportation time is still the transportation mode and distance.

\subsubsection{Transportation Quality (O)}

The evaluation index of transportation quality is mainly the goods loss and damage percentage. In the process of transportation, heavy rain, typhoon, wind, waves and road conditions easily cause damage to the goods. The transportation quality is also considered with the factors that reduce the loss of goods and risk of transit with higher quality. The transportation quality $\mathrm{Q}$ is mainly considered with the possibility of cargo damage in the transport. As for known, the possibilities of cargo damage via road, railway and waterway are $5 \%, 3 \%$ and $2.6 \%$.

The formula of calculating the possibility of cargo damage is as follows.

$$
V=\frac{d_{i}}{d_{i}+d_{j}} \times V_{i}+\frac{d_{j}}{d_{i}+d_{j}} \times V_{j}
$$

$d_{i}, d_{j}$ is the distance of transport mode $\mathrm{i}$, distance of transport mode $\mathrm{j} ; V_{i}, V_{j}$ is the possibility of cargo damage of transport mode $i$, possibility of cargo damage of transport mode $\mathrm{j}$.

\section{Case Study on Ningbo-Zhoushan Port}

Since the initiation of Ningbo-Zhoushan's Rail-sea multimodal transport in 2009, it has witnessed a great improvement, see Figure 1.

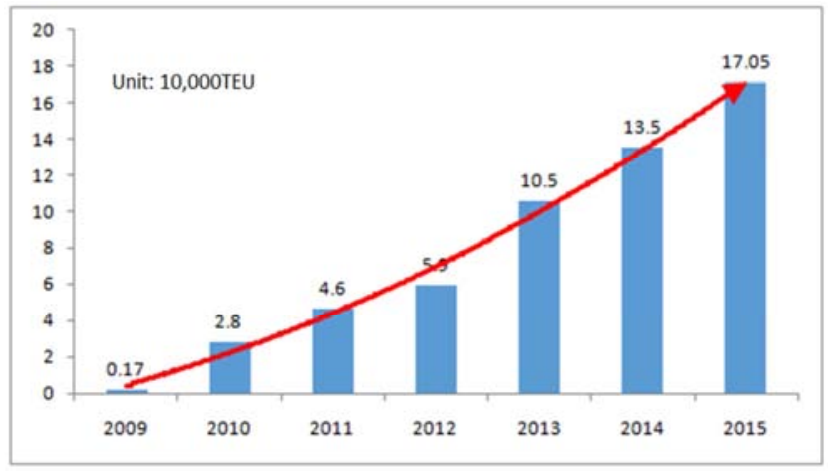

Figure 1. The Container Volume of Rail-sea Multimodal Transport of Ningbo-Zhoushan Port from 2009 to 2015.

\subsection{Options of Multimodal Transport from Ningbo-Zhoushan to Chengdu}

This case study of this paper is about the 20 feet container transportation from Ningbo-Zhoushan port to Chengdu, also called Yangtze River Delta to southwest of China. Three 
indexed are considered, including transportation cost, transportation time and transportation quality, in order to choose the best multimodal transportation plan.

In order to make a intuitive comparison, all transport plans from Ningbo-Zhoushan port to Chengdu are listed in Table 2. The distance of road, railway and waterway transport among Ningbo-Zhoushan, Chongqing and Chengdu are listed in Table 3 .

Table 2. The Twenty Feet Container Transport Plans from Ningbo-Zhoushan Port to Chengdu.

\begin{tabular}{ll}
\hline Transport plan & Combination of different transportation modes \\
\hline F1 & Road transportation \\
F2 & Railway transportation \\
Ningbo-Zhoushan--(railway)--Chongqing--(Road)--C \\
hengdu \\
Ningbo-Zhoushan--(waterway)--Chongqing--(Road)-- \\
F4 \\
Chengdu \\
F5 & $\begin{array}{l}\text { Ningbo-Zhoushan--(waterway)--Chongqing--(Railwa } \\
\text { y)--Chengdu }\end{array}$ \\
\hline
\end{tabular}

Table 3. The Distance among Ningbo-Zhoushan, Chongqing and Chengdu.

\begin{tabular}{llll}
\hline Distance & $\begin{array}{l}\text { Ningbo-Zhoushan } \\
\text { to Chongqing }\end{array}$ & $\begin{array}{l}\text { Chongqing to } \\
\text { Chengdu }\end{array}$ & $\begin{array}{l}\text { Ningbo-Zhoushan } \\
\text { to Chengdu }\end{array}$ \\
\hline Road & 1830.4 & 325 & 2107 \\
Railway & 2488 & 315 & 2803 \\
Waterway & 2547 & $/$ & $/$ \\
\hline
\end{tabular}

With the formula mentioned above, the value of every index of multimodal transport is calculated and shown in Table 4.

Table 4. The Data about Twenty Feet Container Transport from Ningbo-Zhoushan Port to Chengdu.

\begin{tabular}{llllll}
\hline Transport plan & F1 & F2 & F3 & F4 & F5 \\
\hline $\begin{array}{l}\text { Transportation cost } \\
\text { (RMB) }\end{array}$ & 12642 & 4294.49 & 5786.04 & 5111 & 3834.45 \\
$\begin{array}{l}\text { Transportation cost (Hour) } \\
\text { Possibility of cargo }\end{array}$ & 23.4 & 35.03 & 34.07 & 109.73 & 110.07 \\
damage & 0.05 & 0.03 & 0.0323 & 0.0287 & 0.0264 \\
\hline
\end{tabular}

The unitary matrix and relative indexes is calculated as follows.

$$
\begin{gathered}
\left(X_{i j}^{\prime}\right)_{m \times n}=\left[\begin{array}{ccccc}
0.399204496 & 0.135609849 & 0.182709475 & 0.161393306 & 0.121082873 \\
0.074927954 & 0.112167787 & 0.10909382 & 0.351360871 & 0.352449568 \\
0.298685783 & 0.17921147 & 0.192951016 & 0.171445639 & 0.157706093
\end{array}\right] \\
E\left(X_{1}\right)=0.930830554, E\left(X_{2}\right)=0.880001757, E\left(X_{3}\right)=0.981780247 \\
H_{1}=0.069169446, H_{2}=0.119998243, H_{3}=0.018219753 \\
\theta_{1}=0.333527649, \theta_{2}=0.578618655, \theta_{3}=0.087853696
\end{gathered}
$$

The weighted and standardized matrix is calculated as follows.

$$
\left(V_{i j}\right)_{m \times n}=\left[\begin{array}{ccccc}
0.133145737 & 0.045229634 & 0.060938662 & 0.05382913 & 0.040384486 \\
0.043354712 & 0.064902374 & 0.063123719 & 0.203303955 & 0.203933895 \\
0.02624065 & 0.01574439 & 0.01695146 & 0.015062133 & 0.013855063
\end{array}\right] \text { Positive and negative ideal solutions }
$$
are calculated as follows.

$$
\begin{aligned}
& V^{+}=(0.040384486,0.043354712,0.013855063) \\
& V^{-}=(0.133145737,0.203933895,0.02624065)
\end{aligned}
$$

The positive and negative distances and their proximities are calculated and shown in Table 5.

Table 5. The Positive and Negative Distances and Their Proximities of Different Transport Plans.

\begin{tabular}{llllll}
\hline Transport plan & F1 & F2 & F3 & F4 & F5 \\
\hline$d^{+}$ & 0.004379026 & 0.000245673 & 0.000411438 & 0.012882988 \\
$d^{-}$ & 0.012892837 & 0.013653445 & 0.01266436 & 0.012892837 \\
C & 0.746464747 & 0.982324535 & 0.968534406 & 0.003259194 \\
\hline
\end{tabular}

Based on analysis of the indexes of $\mathrm{P}, \mathrm{T}$ and $\mathrm{Q}$, The best transport plan of 20 feet container from Ningbo-Zhoushan to Chengdu is the plan F2, direct railway transport. The next transport plan is F3, goods transported by rail from Ningbo-Zhoushan to Chongqing and then road from Chongqing to Chengdu.

\subsection{Options of Multimodal Transport from Ningbo-Zhoushan to Guiyang}

Referred to the case of transportation of Ningbo-Zhoushan port to Chengdu, five kinds of transportation plan of the positive and negative distance and proximity from 
Ningbo-Zhoushan to Guiyang are shown in Table 6.

Table 6. The Positive and Negative Distance and Proximity of Twenty feet Container Transport from Ningbo-Zhoushan to Guiyang

\begin{tabular}{llllll}
\hline Transport plan & F1 & F2 & F3 & F4 & F5 \\
\hline$d^{+}$ & 0.001155804 & 0.000530097 & 0.000541183 & 0.018231057 & 0.018331178 \\
$d^{-}$ & 0.014114135 & 0.013296707 & 0.012097657 & 0.004661823 & 0.005813535 \\
$\mathrm{C}$ & 0.924308539 & 0.961661634 & 0.957180942 & 0.203636362 & 0.240778795 \\
\hline
\end{tabular}

Based on analysis of the indexes of $\mathrm{P}, \mathrm{T}$ and $\mathrm{Q}$, The best transport plan of 20 feet container from Ningbo-Zhoushan to Guiyang is the plan F2, direct railway transport.

\subsection{Options of Multimodal Transport from Ningbo to Kunming}

Similarly, five kinds of transportation plan of the positive and negative distance and proximity from Ningbo-Zhoushan to Kunming are shown in Table 7.

Table 7. The Positive and Negative Distance and Proximity of Twenty Feet Container Transport from Ningbo-Zhoushan to Kunming.

\begin{tabular}{llllll}
\hline Transport plan & F1 & F2 & F3 & F4 & F5 \\
\hline$d^{+}$ & 0.001353278 & 0.000781294 & 0.000645061 & 0.014330496 \\
$d^{-}$ & 0.013160596 & 0.012278418 & 0.011409133 & 0.003354549 \\
C & 0.906759696 & 0.940175248 & 0.946486621 & 0.189682793 & 0.005313349 \\
\hline
\end{tabular}

The best transport plan of 20 feet container from Ningbo-Zhoushan to Kunming is the plan F3, goods transported by rail from Ningbo-Zhoushan to Chongqing and then road from Chongqing to Kunming. Plan F2 (direct railway transport) is second to plan F3.

In addition, past five years's data are collected, including rail-sea multimodal transport volume of Ningbo-Zhoushan port and the GDP and total import and export trade of
Zhejiang, Hunan and Jiangxi province nearby. According to the analysis of correlation and regression trend prediction, the correlated coefficient between container volume and GDP is 0.9986 , and the correlated coefficient between container volume and total import and export trade is 0.9943 . The increase rate of container rail-sea multimodal transport will be more than $12 \%$ by 2019 in these high economic growing areas, some even $20 \%$.

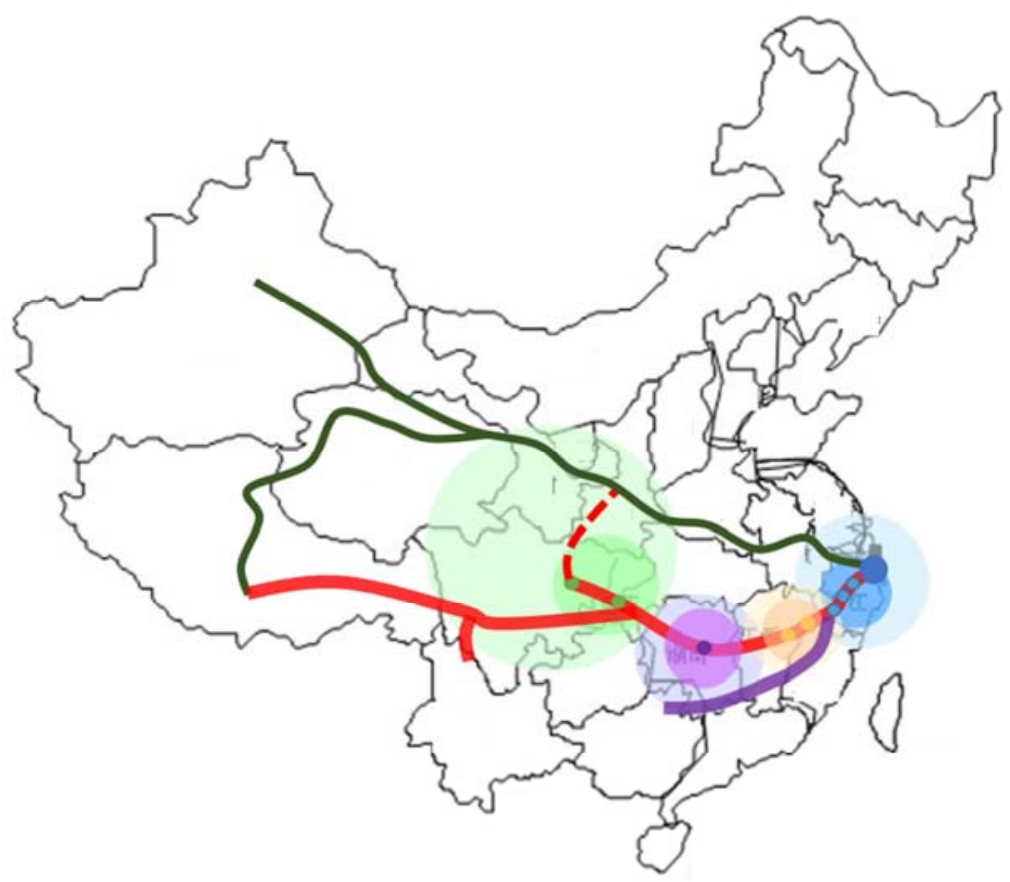

Figure 2. The Route of Multimodal Transport between Ningbo-Zhoushan port and its Dry Port.

\section{Dry Ports Constructions}

\subsection{Extension and Radiation of Port Function}

The investment in the construction and lease of inland site is a superior development form. The inland area has the function of customs declaration, inspection, warehousing, booking and transportation. In dry port, there are institutions of customs, inspection and quarantine supervision. Shipping agency, freight forwarding, aggregation banking, insurance and other shipping elements will be gathered in the 
hinterland [24]. The seamless connection of sea port and dry port via land transport corridors, helps to extend the functions of sea port to the hinterland [25]. The formalities can be completed in the inland areas rather than sea port. It will help to reduce the logistics cost for the enterprise and provide efficient and convenient services for customers [26]. The port business will be extended to the hinterland, further expanding the port market development space and depth.

In addition, the port light asset investment and cooperation agreement with the mainland are adopted. With these two methods enterprises invest limited capital. But these will laid a solid support and protection for sea port to coordinate with government departments, collect market information, provide port consultation and organize railway transportation [27-29].

Overall, the investment of construction and lease inland site, the port light asset investment and cooperation agreement with the mainland are adopted by sea port, helping to extend its functions to inland areas.

\subsection{Investment in the Construction and Operation of Dry Port}

The reason of sea port's investment is the importance attached by enterprises to the logistics system of inland development and cargo expansion. Ningbo Port Railway Limited Company sets up its branch office in Jiangxi and Xinjiang province. Ningbo-Zhoushan sea port invests and constructs dry port in the hinterland, including Yingtan, Shangrao, Quzhou, Jinhua, Yiwu, Xiaoshan, Shaoxing, Cixi and so on. The local import and export enterprises can provide one-stop service, including container booking, customs clearance, inspection, supervision, issuing B/L. The integrated services are provided like packing, unpacking, collecting, distributing, transporting, storing and warehousing [30]. Taking use of port resources, dry port carries out the pickup and delivery container. It will help to increase the container volume and reduce logistics cost, providing economic and convenient logistics services for customers [31].

On one hand, the operation of dry port is dominated by sea port. The dry port is constructed by cooperation of sea port and dry port, self-constructed or joint venture construction. On the other hand, the dry port is constructed separated by sea port or inland area. The inland site are operated together with sea port or inland area [32].

(1) Pickup and delivery of container in dry port

The sites of pickup and delivery of container in dry port are set up along the multimodal transport corridor according to the cargo organization [33]. The operation efficiency of modern multimodal transport with container transportation depends on the transport network. Considered this, the layout of sites of pickup and delivery of container will help to handling the containers reasonably for shippers and carriers along the multimodal transport corridor [34]. The required and empty containers are integrated in superior level for high cooperation of multimodal transport [35].

The site of pickup and delivery of container in dry port is expected to achieve functions shown in Figure 3.

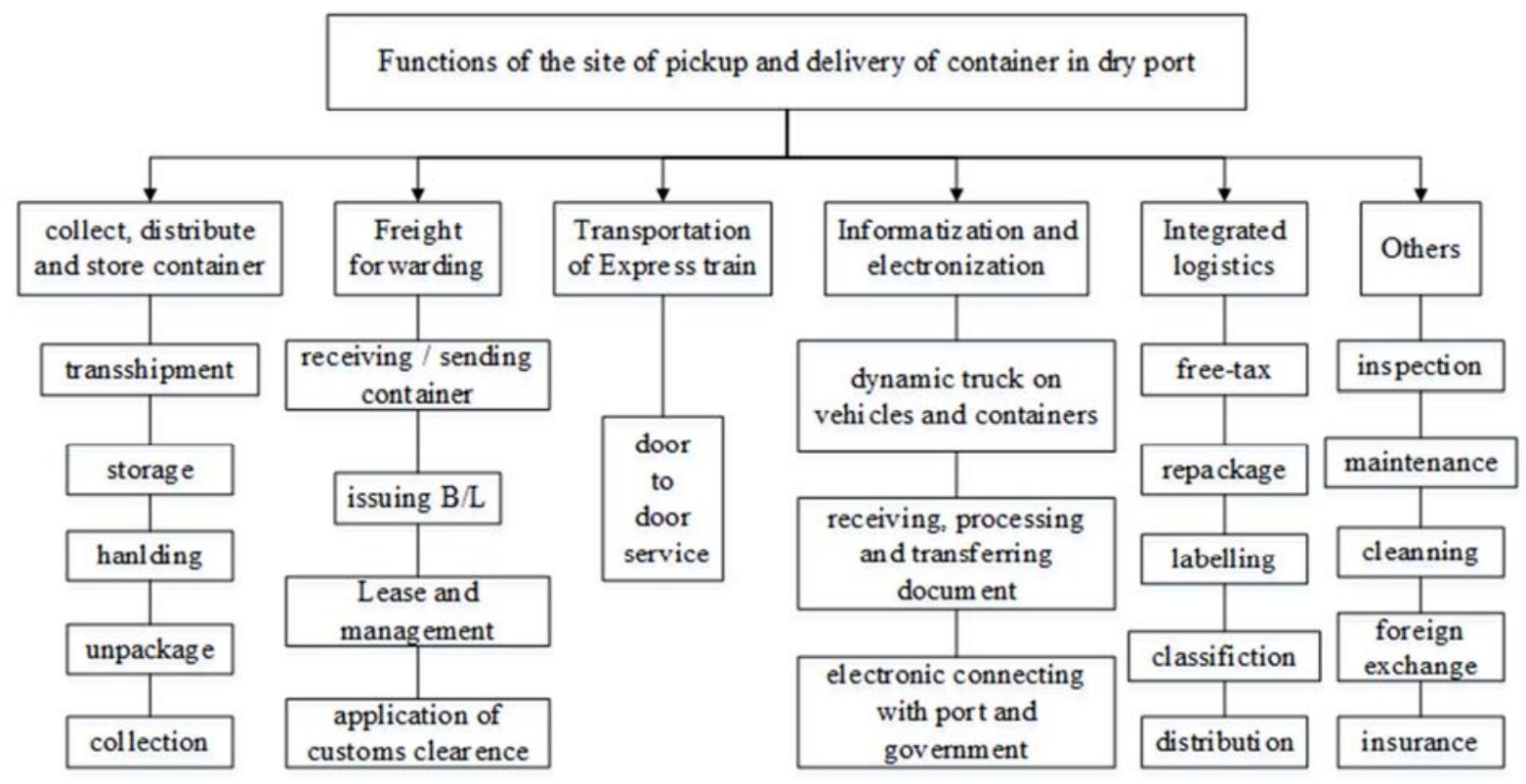

Figure 3. The Functions of the Site of Pickup and Delivery of Container in Dry Port.

A. The function of collecting, distributing and storing container

In the site of pickup and delivery of container in dry port, the services of transferring, storing, handling, unpacking and collecting are provided for import and export cargo. These services help to provide transportation and to assure cargo flow for port and shipping company. They are convenient for main and branch line, multimodal transport and short and long transport. It will help to achieve the container multimodal transport.

B. The function of freight forwarding

The freight forwarder can undertake transportation 
business in the domestic or international market. Authorized by shipper or carrier, the freight forwarder can receive and send out container, issue the bill of lading, lease and manage container, apply to the customs and take up multimodal transport.

C. Transportation of Express train

Transportation of Express train service will help to provide convenient door to door service for shippers.

D. The function of information system management and electronic data transmission

The vehicles and containers can be dynamic trucked on, the transportation document can be received, processed and transferred. Enterprises can connect with port and government via Internet, providing effective information service for customers.

In addition, a maintenance workshop is set up to inspect, maintain and clean vehicles and machines. Exchange settlement and insurance are provided for customers.

Except the basic functions, other business closely related to container multimodal transport can also be set up in the site of pickup and delivery of container in dry port.

E. The function of integrated logistics service

In the site of pickup and delivery of container in dry port, the services of free-tax, repackaging, labeling, classifying and distributing will be provided.

F. Inland port function

In the site of pickup and delivery of container in dry port, the institutions of customs, animal and plant quarantine, health inspection, business inspection and other regulatory agencies are set up for customs clearance services.

(2) Rail-sea multimodal transport

Based on trailer transportation, the road transport network is built among the port, inland area and factory. The operational organization and management method are innovated. The typical trailer mode is formed among container transport areas and close ports, suitable for different regions and goods. This will help to further improve the service standard specification system, land basis for spreading trailer transportation [36].

Ningbo-Zhoushan port takes the organization modes of 'one line with multi-points and pull in turn' and 'cycling trailer'. One line means the corridor between Ningbo-Zhoushan port and its dry port. Multi-points means the ones connecting the dry port with import and export factories. It adapts to the trailer transportation in one province [37].

The rail-sea-road multimodal transport effectively links trailer and rail-sea multimodal transport, as shown in Figure 4. When the heavy container imported to the sea port, it will be transported to the port railway yard. It is sent to inland railway station and then to the factories by trailer transportation for last mile [38]. When imported heavy container is sent to inland factory, it will be unpacked in order to return the empty container to the site of pickup and delivery of container. The empty container will be transported by road to inland railway station and then by railway to the port railway yard [39-40].

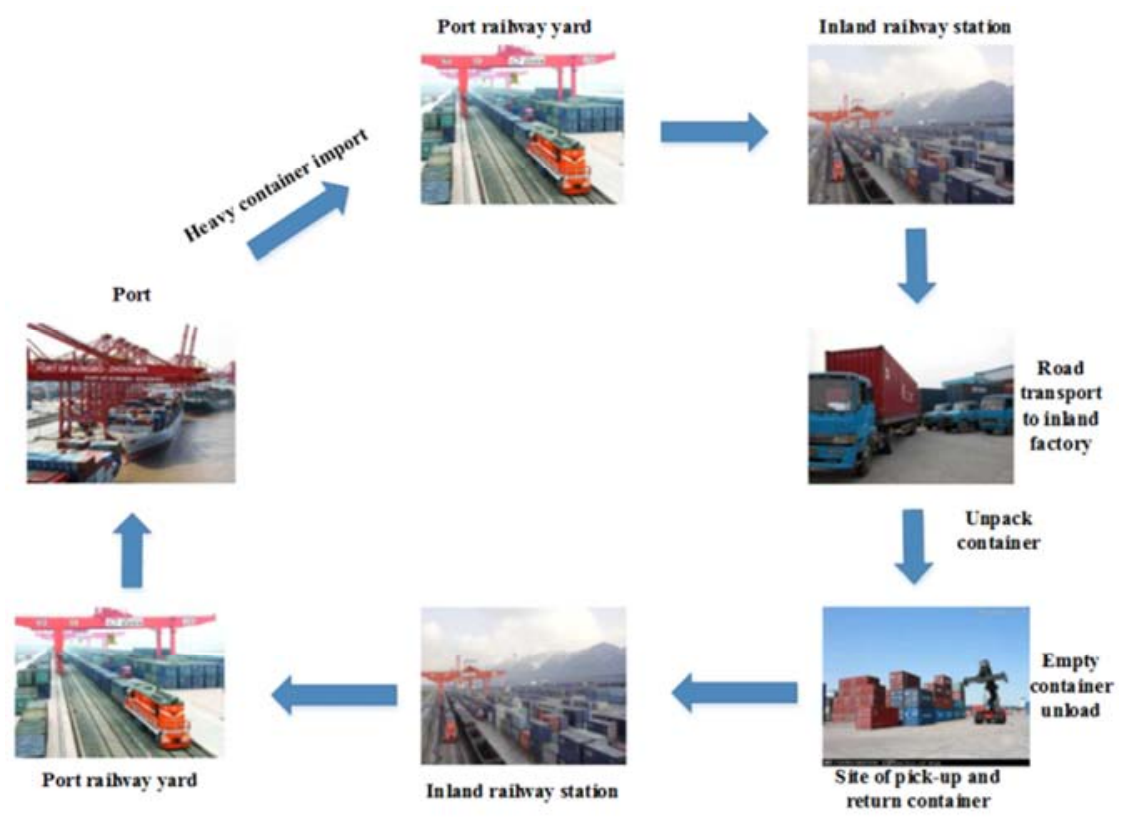

Figure 4. The Rail-sea-road Multimodal Transport between Sea Port and Inland Area.

\section{Conclusions}

Ningbo-Zhoushan port can construct dry port and extend multimodal transport corridors to the southwest. It will help to collect more goods from Sichuan and Guizhou province and improve the corridor competitiveness.
Ningbo-Zhoushan port and its southwest dry port can serve different regions and play the role of complementary advantages and common development. The linkage of logistics function between sea port and dry port can be strengthened. The port logistics function can be extended to the inland dry port station. The transport between inland 
container dry port station and sea port will be transferred to the transport among port itself and close ports. The time fixed rail transport will help to deliver the goods to sea port in time. It will provide international logistics services for import and export goods in the inland areas, and attract more shippers and cargoes.

The construction of dry port and multimodal transport corridor can promote the customs clearance linkage and realize the function of customs multimodal transportation center. It will help to achieve seamless service of whole process with a single document, and achieve the integration of multimodal transport plan.

\section{Acknowledgements}

We would like to thank the China Port Association and Ningbo-Zhoushan Port Group for helping us arrange and coordinate the interviews with different departments and related companies. This study is sponsored by the Shanghai Municipal Government (2015-YJ-E03, 2016-YJ-E02) and Ministry of Transport (2015322268570).

\section{References}

[1] Y Li, Q Dong, S Sun. Dry Port Development in China: Current Status and Future Strategic Directions [J]. Journal of Coastal Research, 2005, 73: 641-646.

[2] Andrius Jarzemskis, Aidas Vasilis Vasiliauskas. Research on dry port concept as intermodal node [J]. Transport, 2007, 22(3): 207-213.

[3] Di Liu, Hualong Yang. Joint slot allocation and dynamic pricing of container sea-rail multimodal transportation $[\mathrm{J}]$. Journal of Traffic and Transportation Engineering, 2015, 2(3): 198-208.

[4] Vasco Reis, J. Fabian Meier, Giuseppe Pace, Roberto Palacin. Rail and multi-modal transport $[\mathrm{J}]$. Research in Transportation Economics, 2013, 41(1): 17-30.

[5] Jia-bin Li, Yong-sik Oh. A Research on Competition and Cooperation Between Shanghai Port and Ningbo-Zhoushan Port [J]. The Asian Journal of Shipping and Logistics, 2010, 26(1): 67-91.

[6] A Rom Kim. A Study on Competitiveness Analysis of Ports in Korea and China by Entropy Weight TOPSIS [J]. The Asian Journal of Shipping and Logistics, 2016, 32(4): 187-194.

[7] S Awadnunez, N Gonzálezcancelas, F Solerflores, A Camareroorive. How should the sustainability of the location of dry ports be measured? A proposed methodology using Bayesian networks and multi-criteria decision analysis [J]. Transport, 2015, 30(3): 312-319.

[8] Y Xie, X Liang, L Ma, H Yan. Empty Container Management and Coordination in Intermodal Transport [J]. European Journal of Operational Research, 2017, 257(1): 223-232.

[9] Wayne K. Talley, ManWo Ng. Hinterland transport chains: Determinant effects on chain choice [J]. International Journal of Production Economics, 2017, 185: 175-179.

[10] S Zhang, Y Gao, Wei, H Jia. Study on problems of dry ports planning based on supply chain management [J]. Lecture Notes in Computer Science, 2012, 2142: 1-4.

[11] S Hanaoka, MB Regmi. Promoting intermodal freight transport through the development of dry ports in Asia: An environmental perspective [J]. Iatss Research, 2011, 35(1): 16-23.

[12] Samir Awad-Nunez, Nicoletta Gonzalez-Cancelas, Francisco Soler-Flores, Alberto Camarero-Orive. A Methodology for Measuring Sustainability of Dry Ports Location Based on Bayesian Networks and Multi-criteria Decision Analysis [J]. Transportation Research Procedia, 2016, 13: 124-133.

[13] Teodor Gabriel Crainic, Paolo Dell'Olmo, Nicoletta Ricciardi, Antonino Sgalambro. Modeling dry-port-based freight distribution planning [J]. Transportation Research Part C: Emerging Technologies, 2015, 55(6): 518-534.

[14] Xuan Qiu, Jasmine Siu Lee Lam, George Q. Huang. A bilevel storage pricing model for outbound containers in a dry port system [J]. Transportation Research Part E: Logistics and Transportation Review, 2015, 73(1): 65-83.

[15] Jian Li, Bao Jiang. Cooperation Performance Evaluation between Seaport and Dry Port; Case of Qingdao Port and Xi'an Port [J]. International Journal of e-Navigation and Maritime Economy, 2014, 1(12): 99-109.

[16] Anu Bask, Violeta Roso, Dan Andersson, Erkki Hamalainen. Development of seaport-dry port dyads: two cases from Northern Europe [J]. Journal of Transport Geography, 2014, 39(6): 85-95.

[17] Daniela Ambrosino, Anna Sciomachen. Location of Mid-range Dry Ports in Multimodal Logistic Networks [J]. Procedia Social and Behavioral Sciences, 2014, 108(1): 118-128.

[18] Shinya Hanaoka, Madan B. Regmi. Promoting intermodal freight transport through the development of dry ports in Asia: An environmental perspective [J]. IATSS Research, 2011, 35(1): 16-23.

[19] Allan Woodburn. An analysis of rail freight operational efficiency and mode share in the British port-hinterland container market [J]. Transportation Research Part D: Transport and Environment, 2017, 51(3): 190-202.

[20] Adel Hatami-Marbini, Fatemeh Kangi. An extension of fuzzy TOPSIS for a group decision making with an application to tehran stock exchange [J]. Applied Soft Computing, 2017, 52(3): 1084-1097.

[21] Katarzyna Rudnik, Dariusz Kacprzak. Fuzzy TOPSIS method with ordered fuzzy numbers for flow control in a manufacturing system [J]. Applied Soft Computing, 2017, 52(3): 1020-1041.

[22] Sonal Sindhu, Vijay Nehra, Sunil Luthra. Investigation of feasibility study of solar farms deployment using hybrid AHP-TOPSIS analysis: Case study of India [J]. Renewable and Sustainable Energy Reviews, 2017, 73(6): 496-511.

[23] Pascal U. Onu, Xie Quan, Ling Xu, Juliet Orji, Eugene Onu. Evaluation of sustainable acid rain control options utilizing a fuzzy TOPSIS multi-criteria decision analysis model frame work [J]. Journal of Cleaner Production, 2017, 141(10): 612-625.

[24] J Monios. A functional analysis of dry port systems: the case of Spain [J]. Journal of Solid State Chemistry, 2010, 115(1): 92-97. 
[25] Di Liu, Hua-long Yang. Optimal Slot Control Model of Container Sea-Rail Intermodal Transport based on Revenue Management [J]. Procedia - Social and Behavioral Sciences, 2013, 96(6): 1250-1259.

[26] Adrian E. Coronado Mondragon, Chandra S. Lalwani, Etienne S. Coronado Mondragon, Christian E. Coronado Mondragon, Kulwant S. Pawar. Intelligent transport systems in multimodal logistics: A case of role and contribution through wireless vehicular networks in a sea port location [J]. International Journal of Production Economics, 2012, 137(1): 165-175.

[27] Anastasija Bolkovska, Julija Petuhova. Simulation-based Public Transport Multi-modal Hub Analysis and Planning [J]. Procedia Computer Science, 2017, 104: 530-538.

[28] Congli Hao, Yixiang Yue. Optimization on Combination of Transport Routes and Modes on Dynamic Programming for a Container Multimodal Transport System [J]. Procedia Engineering, 2016, 137: 382-390.

[29] Ling Zhu, M. Deniz Guner-Ozbek, Hong Yan. A study of liabilities of multimodal transport operators in China [J]. Research in Transportation Economics, 2012, 35(1): 58-65.

[30] Xavier Schepler, Stefan Balev, Sophie Michel, Eric Sanlaville. Global planning in a multi-terminal and multi-modal maritime container port [J]. Transportation Research Part E: Logistics and Transportation Review, 2017, 100(4): 38-62.

[31] P. Phani Kumar, Manoranjan Parida, Mansha Swami. Performance Evaluation of Multimodal Transportation Systems [J]. Procedia - Social and Behavioral Sciences, 2013, 104(2): 795-804.

[32] Tao Zeng, Dawei Hu, Guolang Huang. The Transportation Mode Distribution of Multimodal Transportation in Automotive Logistics [J]. Procedia - Social and Behavioral Sciences, 2013, 96(6): 405-417.
[33] G Georgoulas. Metaheuristic Approaches for Scheduling the Trieste-Fernetti Pickup and Delivery Service [J]. IFAC Proceedings Volumes, 2013, 46(13): 514-519.

[34] Lopez Charles. Sea-river shipping competitiveness and its geographical market area for the Rhone-Saone corridor [J]. Journal of Transport Geography, 2008, 16(2): 100-116.

[35] A. M. Arof, R. MD Hanafiah, I. U. J. Ooi. A Delphi Study on the Potential Benefits and Obstacles of Interstate Short Sea Shipping in Archipelagic Southeast Asia [J]. International Journal of e-Navigation and Maritime Economy, 2016, 5: 97-110.

[36] Benjamin Jansen, Pieter C. J. Swinkels, Geert J. A. Teeuwen, Babette van Antwerpen de Fluiter, Hein A. Fleuren. Operational planning of a large-scale multi-modal transportation system [J]. European Journal of Operational Research, 2004, 156(1): 41-53.

[37] Stefano Carrese, Luigi Tatarelli. Optimizing the stacking of the Intermodal Transport Units in an inland terminal: an heuristic procedure [J]. Procedia - Social and Behavioral Sciences, 2011, 20: 994-1003.

[38] Gordon Wilmsmeier, Jason Monios, Jean-Paul Rodrigue. Drivers for Outside-In port hinterland integration in Latin America: The case of Veracruz, Mexico [J]. Research in Transportation Business \& Management, 2015, 14(3): 34-43.

[39] Stefan Schroeder, Michael Zilske, Gernot Liedtke, Kai Nagel. Towards a Multi-Agent Logistics and Commercial Transport Model: The Transport Service Provider's View [J]. Procedia Social and Behavioral Sciences, 2012, 39: 649-663.

[40] M. SteadieSeifi, N. P. Dellaert, W. Nuijten, T. Van Woensel, R. Raoufi. Multimodal freight transportation planning: A literature review $[\mathrm{J}]$. European Journal of Operational Research, 2014, 233(1): 1-15. 